\title{
Portable liquid oxygen and exercise ability in severe respiratory disability
}

\author{
R M Leach, A C Davidson, S Chinn, C H C Twort, I R Cameron, N T Bateman
}

\begin{abstract}
Background The development of portable liquid oxygen systems, capable of delivering high flow rate oxygen for long periods, justifies reassessment of the value of supplemental oxygen to aid exercise tolerance in patients with chronic respiratory insufficiency. The type of exercise test and the low oxygen flow rates previously used may account for the variable and often poor responses to supplemental oxygen reported in earlier studies.
\end{abstract}

Methods The walking tolerance of $\mathbf{3 0}$ patients with severe respiratory disability was measured while they were breathing air and increasing doses of supplemental oxygen $(2,4,61 / \mathrm{min})$ by using both the standard six minute walking test and an endurance walking test. To assess the initial learning effect and repeatability of the walking tests, three six minute walks and three endurance walks were performed on day 1 and a single walk of each type on days 2,3 , and 14. In addition, oxygen dosing studies were performed on days 2 and 3 after the initial baseline walking tests. Each dosing study comprised four endurance walking tests or four six minute walking tests with patients breathing either air at a flow rate of $41 / \mathrm{min}$ from a portable cylinder or supplemental oxygen at a flow rate of 2,4 or $61 / \mathrm{min}$ from a portable liquid oxygen supply. The order of the tests was randomised. Walking distance with each flow rate of oxygen was compared with walking distance with patients carrying cylinder air and for the initial unburdened walks. Breathlessness was assessed by visual analogue scoring on completion of each walk.

Results Exercise ability and breathlessness were significantly improved with supplemental oxygen and this benefit outweighed the reduction in performance resulting from carrying the portable device. Supplemental oxygen at flow rates of 2,4 , and $61 / \mathrm{min}$ increased mean endurance walking distances by $37.9 \%$, $67.7 \%$ and $85.0 \%$ and six minute walking distances by $19 \cdot 2 \%, 34 \cdot 5 \%$, and $36 \cdot 3 \%$ by comparison with distances when the patient was carrying air with a flow rate of
4 1/min. The additional work of carrying the portable gas supply reduced endurance walking distance by $22 \cdot 2 \%$ and six minute walking distance by $14 \cdot 1 \%$ by comparison with a baseline unburdened walk. Comparison of supplemental oxygen at 2,4 , and $61 / \mathrm{min}$ with the baseline unburdened performance showed increased endurance walking distances of $7 \cdot 3 \%, 30 \cdot 4 \%$, and $43.9 \%$ and six minute walking distances of $2 \cdot 3 \%, 15 \cdot 5 \%$, and $17 \cdot 0 \%$. Walking distance was increased by more than $50 \%$ by comparison with an unburdened walk in seven patients with the endurance walking test but in only three patients with the six minute walking test. The benefit was similar in patients with obstructive and with interstitial lung disease. Individual responses were variable and only desaturation during the baseline walk in patients with obstructive lung disease had any predictive value for benefit with oxygen.

Conclusion As there was no clear relation between response to oxygen therapy and the patients' characteristics, assessment for supplemental oxygen therapy will depend on exercise testing. It is suggested that portable oxygen should be considered only if a patient shows a $50 \%$ improvement in exercise ability with high flow rate oxygen (4-6 1/min) by comparison with an unburdened walk.

\section{(Thorax 1992;47:781-789)}

Supplemental oxygen increases exercise endurance and reduces subjective breathlessness in both obstructive ${ }^{1-3}$ and interstitial ${ }^{45}$ lung disease. Improvement depends on the flow rate or "dose" of supplemental oxygen ${ }^{46}$ and the type of exercise test used. ${ }^{36}$ The value of supplemental oxygen carried by the patient in the management of chronic respiratory insuffiency remains controversial. ${ }^{67}$ In obstructive lung disease the improvement in exercise ability with low flow rates of supplemental oxygen is small when measured in terms of the distance covered in a timed walk ${ }^{367}$ and may be cancelled out by the additional work of carrying the cylinder. ${ }^{7}$ In practice, the short duration of supply of cylinder (gaseous) oxygen, even at low flow rates, has limited its potential use. The 
recent development of portable liquid oxygen systems capable of providing high flow rates for relatively long periods has justified reassessment of this potential treatment for patients with chronic lung disease.

The timed walking test is widely used to assess exercise ability ${ }^{89}$ and the response to treatment. ${ }^{37} \mathrm{~A}$ learning effect has been described for the six minute walk and shown to invalidate the results of some intervention studies. ${ }^{10}$ Previous studies have shown greater benefit with supplemental oxygen when exercise ability was measured by endurance testing. ${ }^{146}$ The learning effects and repeatability of the endurance walk have not previously been assessed.

The aims of this study were (1) to compare the learning effect and repeatability of an endurance walk with those of a timed six minute walk; (2) to assess walking ability with increasing flow rates of portable liquid oxygen in patients with obstructive and interstitial lung disease; (3) to compare an endurance test with the conventional six minute walk in the assessment of the benefit of supplemental oxygen; (4) to measure the deleterious effect of carrying a portable system on tolerance of walking; (5) to determine what features, if any, might help in the selection of patients for treatment.

\section{Methods \\ SUBJECTS}

Patients with severely reduced exercise tolerance secondary to chronic respiratory disease and no previous experience of exercise testing were enrolled from the outpatient clinic. Thirty patients were studied, of whom 20 had chronic obstructive airways disease and 10 had interstitial lung disease (five cryptogenic fibrosing alveolitis, three sarcoidosis, two asbestosis). Angina, impaired left ventricular function, and locomotor disability that may have limited exercise tolerance were exclusion criteria and patients were studied only when in a clinically stable state. Informed consent and the approval of the hospital ethical committee were obtained.

\section{WALKING TESTS}

Exercise ability was assessed by the standard six minute walk and by an endurance walk. Both exercise tests were performed in an enclosed hospital corridor and the starting point and direction of walking varied between tests. The six minute walk was performed as previously described ${ }^{89}$ and patients were encouraged to walk as far as possible, stops being allowed if necessary, in the six minutes. In the endurance walk the subject was instructed to walk as far as possible (at a pace as though late for an appointment) and to stop when unable to go any further. The endurance time and distance walked were recorded. Arterial oxygen saturation was measured by portable ear oximetry (Ohmeda, Biox 3740 pulse oximeter) before, during, and on completion of all walking tests. Walking tests were performed on three consecutive days $(1,2,3)$ and two weeks later (day 14). Conditions were stan- dardised for the time of testing, bronchodilator treatment, and absence of smoking. The patients fasted for at least 90 minutes before each test and a recovery period of 45 minutes was allowed between each test.

\section{LEARNING EFFECTS AND REPEATABILITY OF THE \\ WALKING TESTS}

Three "unburdened" walking tests of each type were performed on day 1 . The first test was randomly selected and subsequent tests were alternately a six minute walk and an endurance walk. On days 2,3 , and 14 , a single unburdened endurance walk and six walks of six minutes were performed in the order selected for day 1 . Six endurance walks and six walks of six minutes were available for the assessment of the initial learning effect and the day to day repeatability for each patient. Two patients, with chronic obstructive airways disease, were unable to perform six tests on day 1 and were asked to complete three endurance walks and one six minute walk.

\section{OXYGEN DOSING STUDIES}

Oxygen dosing studies were performed on days 2 and 3, after the initial baseline unburdened endurance and six minute walks described above. The patient performed four walking tests carrying supplemental oxygen or air on each day. The six minute walking test was performed on one day and the endurance walking test on the other, the order being randomly allocated. The effect of different flow rates of oxygen on exercise tolerance was assessed by comparison of the six minute and endurance walking distances at each flow rate, and compared with the results of the same tests with the patient carrying air at a flow rate of 41 / min and also with the results of the initial baseline unburdened tests. Oxygen at a flow rate of 2,4 or $61 / \mathrm{min}$ was supplied from a Care Ease portable liquid oxygen pack (Omnicare Ltd, Winchester: weight $1.5 \mathrm{~kg}$ empty, $3.5 \mathrm{~kg}$ full). Air at a flow rate of $41 / \mathrm{min}$ was supplied from a sham liquid oxygen system in which a 1801 type D gas cylinder was encased in an emptied Care Ease pack (weight $3 \mathrm{~kg}$ ), to be indistingishable from the liquid oxygen system (liquid air could not be carried in the Care Ease pack). An MC oxygen face mask (Henley Medical Supplies) was used for all patients. At oxygen flow rates of 2,4 and $61 / \mathrm{min}$ the inspired oxygen concentrations were about $28 \%, 40 \%$, and $53 \%$ (manufacturer's specifications). The subject and the investigator were blinded to the flow rate and type of gas supplied, although in practice the investigator was frequently able to determine those patients having oxygen from the oxygen saturation shown by ear oximetry. Encouragement was given at 20 second intervals and standardised to avoid investigator bias. ${ }^{10}$ The same investigator supervised all the walking studies. The order of the four tests in which the gas was carried by the patient was randomised on each day. At the end of each walk a subjective assessment of breathlessness was given by the visual analogue score, patients being required to score breathlessness on a $10 \mathrm{~cm}$ line marked with "not at all 
Table 1 Characteristics of patients (mean (SD) values) taking part in tests of walking tolerance

\begin{tabular}{|c|c|c|}
\hline & $\begin{array}{l}\text { Obstructive } \\
\text { airways } \\
\text { disease }\end{array}$ & $\begin{array}{l}\text { Restrictive } \\
\text { lung } \\
\text { disease }\end{array}$ \\
\hline $\begin{array}{l}\text { No of patients } \\
\text { Male:female }\end{array}$ & $\begin{array}{l}20 \\
12: 8\end{array}$ & $\begin{array}{l}10 \\
8: 2\end{array}$ \\
\hline $\begin{array}{l}\text { Age (years) } \\
\mathrm{FVC}(1) \\
\mathrm{FEV}_{1}(\mathrm{l}) \\
\mathrm{KCO}^{\star}(\%) \\
\mathrm{TLCO}^{\star}(\%) \\
\mathrm{PaO}_{2} \text { resting }(\mathrm{kPa}) \\
\mathrm{PaCO}_{2} \text { resting }(\mathrm{kPa}) \\
\mathrm{PaO}_{2} \text { after exercise }(\mathrm{kPa})\end{array}$ & $\begin{array}{cl}63.4 & (7 \cdot 2) \\
1.94 & (0.51) \\
0.74 & (0.25) \\
61.8 & (29.0) \\
42.1 & (16.9) \\
8.74 & (2.38) \\
5.55 & (1.26) \\
7.82 & (2.97)\end{array}$ & $\begin{array}{cl}62 \cdot 0 & (9 \cdot 6) \\
2 \cdot 47 & (1 \cdot 04) \\
1 \cdot 87 & (0 \cdot 79) \\
60 \cdot 4 & (19 \cdot 3) \\
41 \cdot 1 & (21 \cdot 5) \\
9 \cdot 44 & (1 \cdot 85) \\
4 \cdot 87 & (0.92) \\
8 \cdot 10 & (2 \cdot 74)\end{array}$ \\
\hline
\end{tabular}

*Not available for all 30 patients: KCO and TLCo are for 29 patients and $\mathrm{PaO}_{2}$ after exercise for 25 patients.

FVC-forced vital capacity; $\mathrm{FEV}_{1}$-forced expiratory volume in one second; $\mathrm{KCO}$-transfer coefficient; TLCOtransfer factor for carbon monoxide; $\mathrm{PaO}_{2}$-arterial oxygen tension; $\mathrm{PaCO}_{2}$-arterial carbon dioxide tension.

breathless" at one end and "extremely breathless" at the other end. ${ }^{11}$ The responses were read to the nearest centimeter on the visual analogue scale. On completion of the four walks comprising each dosing study the patient was asked to grade the walks from the easiest to the most difficult. The two patients with chronic obstructive airways disease who were unable to complete the repeatability tests did not perform the six minute walk at a supplemental oxygen flow rate of $6 \mathrm{l} / \mathrm{min}$ but completed all four endurance tests.

\section{PULMONARY FUNCTION TESTING}

Forced expiratory volume $\left(\mathrm{FEV}_{1}\right)$ and forced vital capacity were measured with a dry gas spirometer (Vitalograph) and total lung capacity (TLC) and residual volume with a constant body plethysmograph (PK Morgan). The single breath method was used to measure the carbon monoxide transfer factor (TLCO) and the transfer coefficient (KCO) was calculated by adjustment for the volume of ventilated lung (BTPS) by the helium dilution method (Morgan transfer test). Blood was drawn from the radial artery before the third endurance test on day 1 and immediately on completion of the walk. Twelve patients with chronic obstructive airways disease were tested for carbon dioxide retention with supplemental oxygen on day 14. Following 30 minutes' predosing with oxygen at a flow rate of $61 / \mathrm{min}$ an arterial blood analysis was performed immediately on completion of an endurance test, and also with $6 \mathrm{l} / \mathrm{min}$ supplemental oxygen.

Table 2 Percentage increase (95\% confidence interval) from first test on day 1 for measures of walking tolerance

\begin{tabular}{|c|c|c|c|}
\hline \multirow[b]{2}{*}{ Day } & \multirow{2}{*}{$\begin{array}{l}\text { Six minute } \\
\text { walk } \\
\text { distance }\end{array}$} & \multicolumn{2}{|l|}{ Endurance walk } \\
\hline & & Distance & Speed \\
\hline $\begin{array}{l}1 \text { (2nd test) } \\
1 \text { (3rd test) } \\
2 \\
3 \\
14\end{array}$ & $\begin{array}{l}8.6(4.9 \text { to } 12.5) \\
17.1(13.1 \text { to } 21.3) \\
14.9(11.1 \text { to } 18.8) \\
19.5(15.6 \text { to } 23.6) \\
17.0(13.2 \text { to } 21.0)\end{array}$ & $\begin{array}{l}3.7(-0.7 \text { to } 8.3) \\
5.3 \quad(0.8 \text { to } 10.0) \\
2.5(-1.9 \text { to } 7.0) \\
3.5(-0.9 \text { to } 8.1) \\
3.1(-1.2 \text { to } 7.7)\end{array}$ & $\begin{array}{l}1.0(-3.2 \text { to } 5.4) \\
0.3(-3.9 \text { to } 4.7) \\
0.2(-4.0 \text { to } 4.6) \\
2.9(-1.4 \text { to } 7.4) \\
0.5(-3.7 \text { to } 4.9)\end{array}$ \\
\hline
\end{tabular}

STATISTICAL ANALYSIS

As a proportional relationship was found between the means and the standard deviations, logarithmic transformation ( $\log _{10}$ scale) was used for statistical analysis of the six minute and endurance walking distances and the speed of walking in the endurance test. ${ }^{12}$ The results are reported as the geometric means and $95 \%$ ranges or confidence intervals as appropriate.

The learning effect for the walking tests was determined from a two way analysis of variance (that is, by test order within subject), and where a test order effect was found the part due to a learning effect was separated from subsequent variation. Mean differences from the first test and $95 \%$ confidence intervals on the log scale were antilogged to give percentage increases. The variation between tests not influenced by a learning effect was used to estimate repeatability. ${ }^{13}$

Decreases in walking distances and speed when carrying the portable device, by comparison with performance during a baseline unburdened walk, were analysed by paired $t$ tests. The mean change and $95 \%$ confidence interval on the log scale were antilogged to give a percentage decrease and $95 \%$ confidence interval. The mean increase and $95 \%$ confidence intervals at each flow rate of oxygen $(2,4$ and $6 \mathrm{l} / \mathrm{min})$ by comparison with results of the test with air $(4 \mathrm{l} / \mathrm{min})$ were calculated similarly. The overall significance of the increases in distance and endurance speed with oxygen flow rate were obtained from a within subject analysis of variance of walking distance by oxygen flow rate (that is, generalisation of the paired $t$ test to four oxygen groups $(0,2,4,61 /$ min)). The reduction in percentage oxygen saturation during the walk was analysed similarly but without logarithmic transformation. Subjective benefit as measured on a visual analogue scale was analysed between oxygen levels by means of the sign test for matched pairs. The oxygen effect was further analysed for differences between the patients with obstructive and with interstitial lung disease.

To assess which patients benefit from supplemental oxygen, the improvement in walking distance and endurance speed between an unburdened walk and a walk with supplemental oxygen at a flow rate of $4 \mathrm{l} / \mathrm{min}$ was related to several characteristics of the patients by means of multiple regression.

\section{Results}

Patients' characteristics are reported in table 1 . In patients with chronic obstructive airways disease resting arterial oxygen tension $\left(\mathrm{PaO}_{2}\right)$ was below $8.5 \mathrm{kPa}$ in $12,8.5-11 \mathrm{kPa}$ in three, and above $11 \mathrm{kPa}$ in five. In patients with interstitial lung disease arterial $\mathrm{PaO}_{2}$ was below $8.5 \mathrm{kPa}$ in five, $8.5-11 \mathrm{kPa}$ in two, and above $11 \mathrm{kPa}$ in three. $\mathrm{PaO}_{2}$ had fallen by more than $1.3 \mathrm{kPa}$ and arterial saturation as measured by ear oximetry by more than $10 \%$ at completion of an unburdened endurance walk in 11 patients with chronic obstructive airways disease and five patients with interstitial lung disease, with a resting $\mathrm{PaO}_{2}$ of less than $8.5 \mathrm{kPa}$. Arterial saturation alone fell by more than $10 \%$ 
Table 3 Distribution of walking tolerance and percentage decrease due to carrying the portable system (cylinder air at 4 (l/min)

\begin{tabular}{lll}
\hline & $\begin{array}{l}\text { Unburdened } \\
\text { (geometric mean (95\% range)) }\end{array}$ & $\begin{array}{l}\text { Percentage decrease with } \\
\text { portable system } \\
\text { (geometric mean (95\% confidence interval)) }\end{array}$ \\
\hline Six minute distance (m) & $266(81$ to 868$)$ & $14 \cdot 1 \star \star \star(10 \cdot 3$ to $17 \cdot 8)$ \\
Endurance distance $(\mathrm{m})$ & $116(38$ to 354$)$ & $22 \cdot 2^{\star \star \star}(16 \cdot 3$ to $27 \cdot 7)$ \\
Endurance speed $(\mathrm{m} / \mathrm{min})$ & $86(53$ to 139$)$ & $5 \cdot 7^{\star}(1 \cdot 3$ to $9 \cdot 9)$ \\
\hline
\end{tabular}

${ }^{\star} p<0.05 ;{ }^{\star \star \star} p<0.001$

in three patients (one with chronic obstructive airways disease, two with interstitial lung disease), the resting $\mathrm{PaO}_{2}$ being $9.6 \mathrm{kPa}$ in one and over $11 \mathrm{kPa}$ in the other two. In the remaining patients reductions in arterial $\mathrm{PaO}_{2}$ and ear oximetry saturation during an unburdened walk were small or did not occur. Carbon dioxide retention occurred in two of 12 patients with chronic obstructive airways disease after predosing and an endurance walk with high flow rate oxygen, arterial carbon dioxide tension
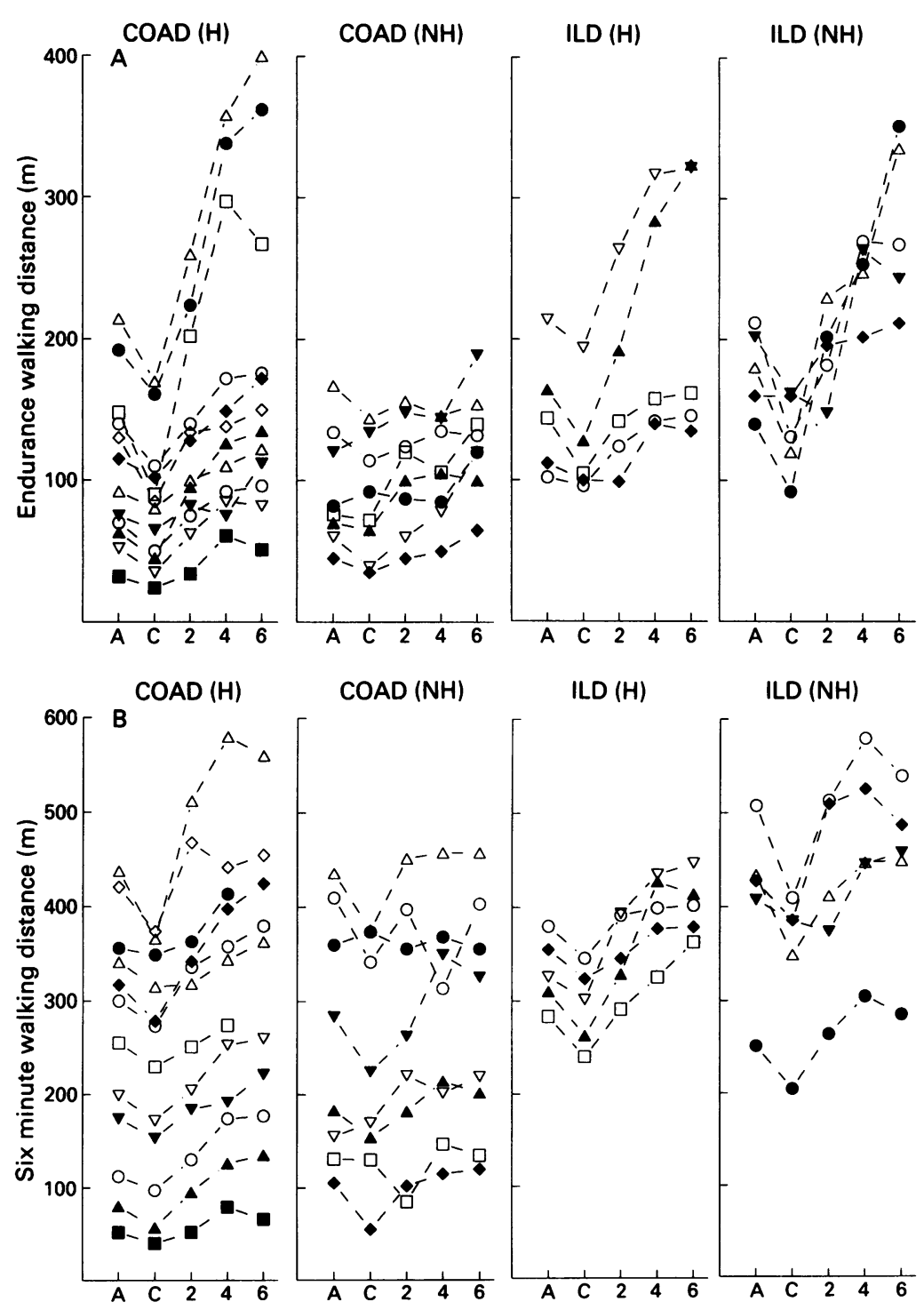

COAD (NH)

ILD (H)

ILD (NH)
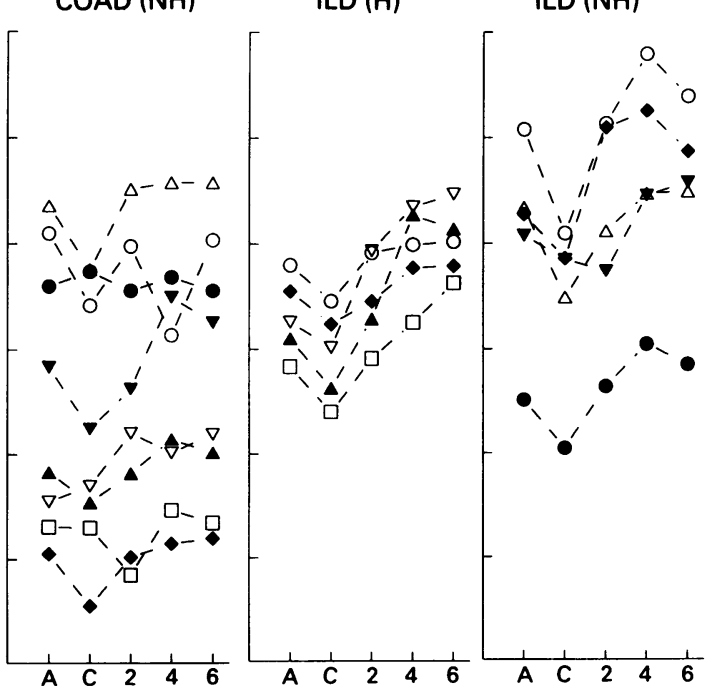

Figure 1 Endurance (top panel) and six minute (bottom panel) walking distances ( $m$ ) in an unburdened walk $(A)$ and walks with the patient carrying cylinder air at a flow rate of 4 l/min (C) or a portable liquid oxygen system at flow rates of $2 \mathrm{l} / \mathrm{min}$ (2), $41 / \mathrm{min}$ (4) and $61 / \mathrm{min}$ (6) for patients with chronic obstructive airways disease (COAD) and interstitial lung disease (ILD). Patients are divided into those with and without resting arterial hypoxaemia $\left(\mathrm{H}=\right.$ resting arterial oxygen tension $\left(\mathrm{PaO}_{2}\right)$ $8.5 \mathrm{kPa}$ or less and $\mathrm{NH}=$ above $8.5 \mathrm{kPa})$.
$\left(\mathrm{PaCO}_{2}\right)$ increasing from $6 \cdot 1$ to $7 \cdot 8 \mathrm{kPa}$ in one and from 5.6 to $6.8 \mathrm{kPa}$ in the other.

\section{THE LEARNING EFFECT AND REPEATABILITY OF} THE WALKING TESTS

The learning effects of the six minute and endurance walks for all 30 patients examined are summarised in table 2 . There was a significant increase in the distances walked in the six minute walks on day $1(p<0.001)$, but no change in the mean distances walked between the third walk on day 1 and the walks on subsequent days $(2,3,14)$. With these values combined, the learning effect for the six minute walk was estimated to be $17 \cdot 1 \%$ (95\% confidence interval (CI) 14.0 to $20 \cdot 4$ ). Overall, the differences in mean walking distance in the endurance test were not statistically significant, but the increase from the first walk on day 1 to the mean of the subsequent walks was significant $(\mathrm{p}<0.05)$ and estimated to be $3.6 \%$ $(95 \%$ CI $0 \cdot 2 \%$ to $7 \cdot 1 \%)$. No learning effect was detectable in speed of walking in the endurance test.

Both the six minute and the endurance walking distances were highly repeatable when learning was complete. The repeatability for a single distance walked is expressed as the $95 \%$ range for single values and was from $-11 \%$ to $+12 \%$ for the six minute walk (on the basis of the third walk on day 1 and subsequent walks) and from $-13 \%$ to $+15 \%$ for the endurance walk (second walk on day 1 and subsequent walks). The change in distance walked by an individual that would represent no improvement or deterioration in response to a given intervention is expressed as the $95 \%$ range for change. For the six minute walk it was from $-15 \%$ to $+18 \%$ and for the endurance walk from $-18 \%$ to $+22 \%$. Endurance walking speed was less repeatable, with a $95 \%$ range for change of $-21 \%$ to $+26 \%$. The intraclass correlation coefficient for the six minute walking distance was 0.99 and for the endurance walking distance 0.98 .

REDUCTION IN WALKING TOLERANCE WITH THE PORTABLE DEVICE

The results of walking tolerance in the baseline unburdened walk and the percentage decrease due to carrying a sham liquid oxygen system (cylinder air at a flow rate of $41 / \mathrm{min}$ ) for all 30 patients are given in table 3. The decreases of $14.1 \%$ and $22 \cdot 2 \%$ in geometric mean walking distance for the six minute and endurance walks were highly significant $(p<0.001)$. There was a small but significant reduction in endurance speed $(p<0.05)$. The mean 
Table 4 Distribution of walking tolerance for patients carrying a cylinder of air, percentage increase in exercise ability with increasing oxygen $\left(\mathrm{O}_{2}\right)$ supplementation compared with cylinder air, mean decrease in percentage desaturation, and median visual analogue score for breathlessness

\begin{tabular}{|c|c|c|c|c|}
\hline & Air cylinder & $2 \mathrm{l} / \mathrm{min} \mathrm{O}_{2}$ & $4 \mathrm{l} / \min \mathrm{O}_{2}$ & $6 \mathrm{l} / \min \mathrm{O}_{2}$ \\
\hline & $\begin{array}{l}\text { Geometric mean } \\
\text { (95\% range) }\end{array}$ & Mean change $(95 \%$ & e interval) & \\
\hline \multirow[t]{2}{*}{$\begin{array}{l}\text { Six minute distance }(\mathrm{m}) \\
\text { Endurance distance }(\mathrm{m}) \\
\text { Endurance speed }(\mathrm{m} / \mathrm{min})\end{array}$} & $\begin{array}{r}228(64 \text { to } 811) \\
90(29 \text { to } 277) \\
81(48 \text { to } 137)\end{array}$ & $\begin{array}{r}19.2 \%(12.7 \text { to } 26.0) \\
37.9 \%(26.6 \text { to } 50.3) \\
2.0 \%(-2.5 \text { to } 2.8)\end{array}$ & $\begin{array}{r}34.5 \%(27.2 \text { to } 42 \cdot 3) \\
67 \cdot 6 \%(53.9 \text { to } 82 \cdot 7) \\
4 \cdot 1 \%(-0.6 \text { to } 8 \cdot 9)\end{array}$ & $\begin{array}{c}36.3 \%(28.9 \text { to } 44 \cdot 1) \\
85.0 \%(69.8 \text { to } 101.5) \\
2.0 \%(-2 \cdot 5 \text { to } 2 \cdot 8)\end{array}$ \\
\hline & Mean (range) & & & \\
\hline \multirow[t]{2}{*}{$\begin{array}{l}\% \text { Desaturation on } 6 \mathrm{MW} \\
\% \text { Desaturation on END }\end{array}$} & $\begin{array}{l}15(1-34) \\
13(0-29)\end{array}$ & $\begin{array}{l}-4 \cdot 8(-2.8 \text { to }-6.9) \\
-3.0(-1.5 \text { to }-4 \cdot 6)\end{array}$ & $\begin{array}{l}-7 \cdot 8(-5.7 \text { to }-9 \cdot 8) \\
-4 \cdot 6(-3.0 \text { to }-6 \cdot 1)\end{array}$ & $\begin{array}{l}-7.9(-5.8 \text { to }-9 \cdot 9) \\
-6 \cdot 4(-4.8 \text { to }-8 \cdot 0)\end{array}$ \\
\hline & Median (range) & & & \\
\hline $\begin{array}{l}\text { Visual analogue score }(\mathrm{cm}) \\
\text { for breathlessness on } 6 \mathrm{MW}\end{array}$ & $9(4$ to 10$)$ & 7 (3 to 9 ) & $5(2$ to 9$)$ & $5(1$ to 8$)$ \\
\hline $\begin{array}{l}\text { Visual analogue score }(\mathrm{cm}) \\
\text { for breathlessness on END }\end{array}$ & $9(7$ to 10$)$ & $7(5$ to 10$)$ & $6(2$ to 7$)$ & $5(2$ to 9$)$ \\
\hline
\end{tabular}

$6 \mathrm{MW}-6$ minute walk; END—endurance walk.

decreases did not differ significantly between patients with obstructive and interstitial lung disease. Mean desaturation was greater when they were carrying a sham system than during an unburdened walk, $1.4 \%$ with the six minute walk and $0.03 \%$ with the endurance walk; but neither value is significantly different from zero $(\mathrm{p}>0 \cdot 1)$.

\section{OXYGEN DOSING STUDIES}

Figure 1 illustrates the six minute and endurance walking distances (in metres) for each of the 30 patients in the unburdened walk, with cylinder air at a flow rate of $41 / \mathrm{min}$, and with supplemental liquid oxygen at flow rates of 2, 4 and $6 \mathrm{l} / \mathrm{min}$. Walking distances and change with oxygen varied considerably between patients. In clinical practice improvement in the individual patient is the important measure rather than the mean increase in a group of patients. Thus the individual data and the number of patients obtaining an improvement greater than the $95 \%$ range for change, or an improvement over $50 \%$ of the baseline walking distance, are reported in addition to the mean responses for the whole group.

\section{Exercise tolerance, desaturation, and breathlessness scores compared with those for walks with cylinder air}

Table 4 reports the mean walking distances and endurance speed (and 95\% range) with the carried sham system (cylinder air) and the corresponding baseline values of percentage desaturation and visual analogue breathlessness score. The mean percentage changes with 2,4 and $6 \mathrm{l} / \mathrm{min}$ supplemental oxygen are also shown in table 4 . The six minute and endurance walking distances were both highly significantly greater $(p<0.001)$ with each oxygen flow rate than with cylinder air. Oxygen flow rates of 4 and $61 / \mathrm{min}$ produced significant improvements in distance tolerance for the six minute and endurance walks by comparison with $21 / \mathrm{min}(\mathrm{p}<0.001)$, but only the endurance test showed a significant improvement of $6 \mathrm{l} / \mathrm{min}$ over $4 \mathrm{l} / \mathrm{min}(\mathrm{p}<$ 0.05). The responses to supplemental oxygen varied considerably in individual patients.
There was no change in endurance walk speed. At all oxygen flow rates improved performance was greater in the endurance walk than in the six minute walking test, significantly so at oxygen flow rates of $4 \mathrm{l} / \mathrm{min}(\mathrm{p}<0.05)$ and $6 \mathrm{l} /$ $\min (p<0.01)$. There was no difference between patients with obstructive and interstitial lung disease.

In comparison with walking with cylinder air, supplemental oxygen at $4 \mathrm{l} / \mathrm{min}$ resulted in an improvement greater than the $95 \%$ range for change (table 2 ) in 25 patients ( 15 with chronic obstructive airways disease, 10 with interstitial lung disease) with endurance walking and 21 patients (14 with chronic obstructive airways disease, seven with interstitial lung disease) with six minute walking. Improvement of greater than $50 \%$ of the distance walked with cylinder air occurred in 18 patients $(11$ with chronic obstructive airways disease, seven with interstitial lung disease) with endurance walking and seven patients (six with chronic obstructive airways disease) with six minute walking.

Supplemental oxygen prevented desaturation during six minute and endurance walking tests $(\mathrm{p}<0.001)$. Breathlessness, as measured by the visual analogue score, was improved in both walking tests $(p<0.001)$. After completion of the four walks with carried gas, the one with cylinder carried air was subjectively declared the most difficult walk by 24 of the 30 patients for both the six minute and the endurance walk. Of the six patients not reporting the one with cylinder air to be the most difficult walk, supplemental oxygen at a flow rate of $21 / \mathrm{min}$ was reported to be the most difficult. All but three patients reported either the 4 or $6 \mathrm{l} / \mathrm{min}$ supplemental oxygen walk to be the easiest.

Exercise tolerance compared with an unburdened walk

The percentage change (and 95\% confidence intervals) in walking distance with carried gas $(0,2,4$ and $61 /$ min supplemental oxygen) by comparison with the baseline unburdened walk is reported in table 5. Supplemental oxygen at a flow rate of $4 \mathrm{l} / \mathrm{min}$ resulted in an improvement 
Table 5 Percentage change in walking tolerance of patients carrying a supply of gas, either cylinder air at a flow rate of $4 \mathrm{l} / \mathrm{min}$ or supplemental oxygen at a flow rate of 2,4 , or $6 \mathrm{l} / \mathrm{min}$, compared with tolerance for unburdened walking

\begin{tabular}{ccc}
\hline & $\begin{array}{l}\text { Six minute walk } \\
\text { (mean \% change (95\% confidence interval)) }\end{array}$ & Endurance walk \\
\hline Air at $41 / \mathrm{min}$ & $-14 \cdot 1 \%(-18 \cdot 6$ to $-9 \cdot 4)$ & $-22 \cdot 2 \%(-28 \cdot 2$ to $-15 \cdot 7)$ \\
Oxygen $21 / \mathrm{min}$ & $2 \cdot 3 \%(-3 \cdot 0$ to $7 \cdot 9)$ & $7 \cdot 3 \%(-1 \cdot 0$ to $16 \cdot 3)$ \\
$41 / \mathrm{min}$ & $15 \cdot 5 \%(9 \cdot 5$ to $21 \cdot 8)$ & $30 \cdot 4 \%(20 \cdot 3$ to $41 \cdot 3)$ \\
$61 / \mathrm{min}$ & $17 \cdot 0 \%(10 \cdot 9$ to $23 \cdot 5)$ & $43.9 \%(32 \cdot 8$ to $56 \cdot 0)$ \\
\hline
\end{tabular}

greater than the $95 \%$ range for change in 17 patients (10 with chronic obstructive airways disease, seven with interstitial lung disease) with endurance walking and 12 patients (eight with chronic obstructive airways disease, 4 with interstitial lung disease) with six minute walking. An improvement of more than $50 \%$ of the unburdened walk was seen in seven patients (five with chronic obstructive airways disease) with endurance walking and three patients (all with chronic obstructive airways disease) with six minute walking.

\section{FACTORS INFLUENCING THE RESPONSE TO SUPPLEMENTAL OXYGEN}

There was no relation between the benefit with supplemental oxygen and the age, sex, baseline spirometric values, and gas transfer of the individual patient. In this study 15 patients with obstructive and seven patients with interstitial lung disease were hypoxaemic at rest $\left(\mathrm{PaO}_{2}<11 \mathrm{kPa}\right)$. The seven patients (five with chronic obstructive airways disease) in endurance walking and three patients (all with chronic obstructive airways disease) in six minute walking who showed improvements of greater than $50 \%$ with supplemental oxygen at $4 \mathrm{l} / \mathrm{min}$ by comparison with an unburdened walk were all hypoxaemic at rest $\left(\mathrm{PaO}_{2}<11 \mathrm{kPa}\right)$. Of the patients walking more than $50 \%$ further with oxygen at $41 / \mathrm{min}$ than with cylinder air, 15 of 18 patients (10 with chronic obstructive airways disease, five with interstitial lung disease) in endurance testing and all seven patients (six with chronic obstructive airways disease) in the six minute walking were hypoxaemic at rest. Of the three patients (two with interstitial lung disease) who were not hypoxaemic $\left(\mathrm{PaO}_{2}>11 \mathrm{kPa}\right)$, one with interstitial lung disease showed arterial desaturation of greater than $10 \%$ on an unburdened walk. Statistical analysis did not yield a predictive value for resting $\mathrm{PaO}_{2}$ but was limited by the small numbers of non-hypoxaemic subjects.

Table 6 reports the mean increases and the variability (as the $95 \%$ range) in walking distance with $4 \mathrm{l} / \mathrm{min}$ supplemental oxygen by comparison with an unburdened walk in patients with obstructive and interstitial lung disease. A weak predictive value $(p<0.05)$ for desaturation with endurance walking in chronic obstructive airways disease is demonstrated. By comparison with an unburdened walk, the mean increase in six minute walking distance with supplemental oxygen $(4 \mathrm{l} / \mathrm{min})$ did not differ between patients with obstructive and interstitial lung disease and the mean and $95 \%$ range were calculated for all 30 patients. The $95 \%$ range for six minute walking distance was from a decrease of $8.4 \%$ to an increase of $58.8 \%$. The endurance walking distance was found to be related to the desaturation measured by ear oximetry during the unburdened walk in patients with chronic obstructive airways disease. Figure 2 shows that the greater the desaturation the greater is the benefit these patients derive from oxygen at $41 / \mathrm{min}$. Exercise tolerance increased by $1 \cdot 7 \%(95 \%$ CI $0.4 \%$ to $3.0 \%$ ) for each $1 \%$ of desaturation calculated from the slope of the regression line for patients with chronic obstructive airways disease (fig 2). At 4 1/min oxygen the $95 \%$ range for endurance walking distance in patients with chronic obstructive airways disease with a desaturation of $16 \%$ during the baseline unburdened endurance walk was estimated to be from a decrease of $6.8 \%$ to an increase of $108 \cdot 8 \%$. Without adjustment for desaturation the estimated $95 \%$ range for patients with chronic obstructive airways disease was from a decrease of $21.5 \%$ to an increase of $111.0 \%$. As a result of the large overlap of the $95 \%$ ranges the predictive value of desaturation is poor.

\section{Discussion}

In the United Kingdom oxygen concentrators are used for the delivery of long term domiciliary oxygen when this is indicated in patients with hypoxaemic cor pulmonale. ${ }^{14-16}$ Mobility is restricted with this form of oxygen supply and many patients are confined to the

Table 6 Variation in the benefit of oxygen supplementation at $4 \mathrm{l} / \mathrm{min}$ in 30 patients, in terms of change in distance walked from the distance of an unburdened walk

\begin{tabular}{|c|c|c|c|c|}
\hline & $\begin{array}{l}\text { Geometric } \\
\text { mean for } \\
\% \text { increase }\end{array}$ & $\begin{array}{l}95 \% \text { range for \% } \\
\text { increase ( } 95 \% \text { range for } \\
\% \text { change if no benefit) }\end{array}$ & $\begin{array}{l}\text { No of patients } \\
\text { with increase above } \\
95 \% \text { range for change }\end{array}$ & $\begin{array}{l}\text { No of patients } \\
\text { with more than } \\
50 \% \text { increase }\end{array}$ \\
\hline Six minute distance $(n=30)$ & $15 \cdot 5$ & -8.4 to $58 \cdot 8(-15$ to +18$)$ & 12 & 3 \\
\hline $\begin{array}{l}\text { Endurance distance } \\
\text { Restrictive lung disease }(n=10) \\
\text { Obstructive airways disease }(n=20)\end{array}$ & $34 \cdot 0$ & $-9 \cdot 1$ to $97 \cdot 5(-18$ to +22$)$ & 7 & 2 \\
\hline $\begin{array}{l}\text { Obstructive airways disease }(n=20) \\
\text { For all patients } \\
\text { For patients with a desaturation of } 16 \% \text { at the } \\
\text { baseline walk }\end{array}$ & $\begin{array}{l}28 \cdot 6 \\
39 \cdot 5\end{array}$ & $\begin{array}{l}-21 \cdot 5 \text { to } 111 \cdot 0(-18 \text { to }+22) \\
-6 \cdot 8 \text { to } 108 \cdot 8\end{array}$ & 10 & 5 \\
\hline
\end{tabular}


Figure 2 Increase in endurance distance with $4 \mathrm{l} /$ min supplemental oxygen expressed as log (endurance distance with $4 \mathrm{l} / \mathrm{min}$ oxygen/unburdened endurance distance) in relation to the percentage desaturation in an unburdened endurance walk in patients with chronic obstructive ( $O$ ) and interstitial (O) lung disease. The dotted line is the regression line for chronic obstructive lung disease and the solid line for interstitial lung disease.

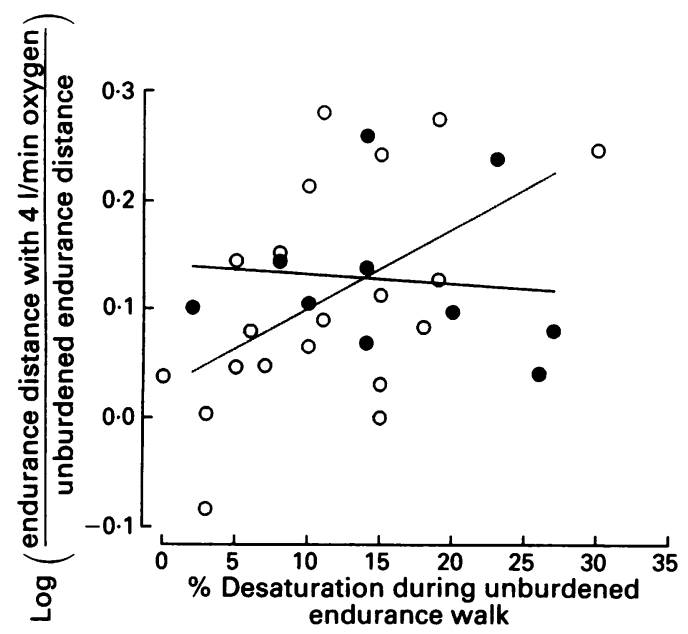

home. ${ }^{17}$ Portable low flow rate cylinders of gaseous oxygen are impractical and there is controversy about whether the reported benefit is worth while. ${ }^{367}$ In the United States and much of Europe lightweight portable liquid oxygen systems capable of delivering high flow rates of oxygen for long periods $(41 / \mathrm{min}$ for four hours) are available for domestic use and are regarded as necessary for the patient's mobility. ${ }^{18}$

The reported improvements in exercise ability and breathlessness with supplemental oxygen are variable. ${ }^{1-5}$ In patients with severe obstructive airways disease secondary to chronic bronchitis or emphysema exercise ability has been found to increase from $8 \%$ to $52 \% .^{367}$ We have previously reported that distance covered in an endurance walk showed a greater benefit in response to oxygen than a timed walk, ${ }^{6}$ and Woodcock et al observed a $28 \%$ improvement in treadmill endurance with oxygen compared with $8 \%$ in a six minute walk. ${ }^{3}$

The results of this study suggest that oxygen enables patients with chronic respiratory insufficiency to perform significantly better in short bursts of more intensive exercise but confers less benefit in self paced exertion. During the endurance walk carrying cylinder air at a flow rate of $41 / \mathrm{min}$ the average distance walked was 90 metres at a speed of 81 metres/ minute (average walking time $1 \cdot 11$ minutes). In comparison, the average distance covered in the six minute walk was 228 metres at a speed of 38 metres/minute (table 4 ). The endurance test also measured a greater improvement in exercise tolerance with each flow rate of supplemental oxygen. Those patients who hurry or exercise to the limit of their ability are therefore the patients most likely to benefit from oxygen. Although endurance testing may be less representative of normal walking than the self paced six minute walk, in severe respiratory insufficiency patients may often have to exercise to the limit of their tolerance-for example, when climbing stairs or during house cleaning. An additional benefit of the endurance test is that there is less within subject variation than in the six minute walking test. In individual patients we observed considerable variation in the time and speed of walking and the number and duration of rests during the six minute walks (unpublished data). The effect of these factors on the sensitivity of the six minute walk is unknown.

The relationship of exercise ability to oxygen flow rate or concentration has not previously been closely examined. We recently showed that cycling endurance time depends on oxygen flow rate in patients with obstructive lung disease. ${ }^{6}$ Cotes et al also reported that endurance time increases progressively with increasing oxygen concentration in patients with interstitial lung disease. ${ }^{4}$ This study extends the findings of these previous reports. Greater benefit is obtained at an oxygen flow rate of $4 \mathrm{l} / \mathrm{min}$ than at $2 \mathrm{l} / \mathrm{min}$, with further benefit at $6 \mathrm{l} / \mathrm{min}$ in the endurance test. The mean response with oxygen was similar for patients with chronic obstructive airways disease and with interstitial lung disease. The change in exercise performance is complicated by the additional work required in carrying the supply of gas. We have found poorer walking tolerance $(14.1 \%$ less in the six minute walk and $22 \cdot 2 \%$ less in the endurance walk) in patients carrying a sham liquid oxygen system (containing cylinder air at $4 \mathrm{l} / \mathrm{min}$ ) than during an unburdened walk. Low flow rates of oxygen may not increase performance when this is compared with performance in an unburdened walk because of the additional work required to carry the portable oxygen system. The results of this study may explain the inconsistency of the results of previous studies, ${ }^{1367}$ in which low flow rate oxygen $(2 \mathrm{l} / \mathrm{min}$ ) and the six minute (or 12 minute) walk have generally been used.

In practice, the value of portable cylinder oxygen is limited by the small capacity (200 $230 \mathrm{l}$ ) and short period of supply even at low flow rates. A flow rate of $21 / \mathrm{min}$ increases six minute walking distance by $19 \cdot 2 \%$ and endurance walking distance by $37.9 \%$ by comparison with a "sham" liquid oxygen system (disguised cylinder air with a flow rate of 41 / min) carried by the patient. When the work of carrying the system is taken into account (that is, performance is compared with that of an unburdened walk), the benefit at $21 / \mathrm{min}$ is only $2.3 \%$ for the six minute walk and $7 \cdot 3 \%$ for the endurance walk. These findings are consistent with those of Leggett et al, in which an $8 \%$ increase in walking distance (12 minute walk) with oxygen was cancelled out by the additional work required when the patient carried the cylinder. ${ }^{7}$

Supplemental oxygen, at higher flow rates, significantly improved exercise tolerance even by comparison with unburdened walking. A potential source of error is that unburdened walks cannot be performed blind and in this study were performed before the oxygen dosing studies (that is, not randomised). This is unlikely to have affected the findings because the response to oxygen was much greater than the variability of the performance in the walking tests (table 1) and the study design avoided incorporation of any learning effects.

Visual analogue scores of the progressive reduction in breathlessness with increasing doses of supplemental oxygen are similar to those reported in previous studies. ${ }^{1920}$ Patients 
were unaware that one of the walking tests would be with disguised cylinder air, but were clearly able to distinguish between carried air and either low or high flow oxygen. Observation by the investigator also suggested that the patients were less distressed on completion of walking tests with oxygen. When questioned about the factors that resulted in their stopping exercise, nine patients reported that exercise had been limited by muscle fatigue rather than breathlessness with oxygen at $61 / \mathrm{min}$, and six spontaneously reported that the breathlessness when they were supplied with oxygen was of a different and less distressing quality. After a period of increased activity with portable oxygen further increases in exercise ability might be expected as a result of muscle training.

The benefits of supplemental oxygen for exercise performance were highly variable and the importance of examining individual patients' responses is seen in figure 1 . As in a previous study, ${ }^{6}$ we were unable to find a correlation between age, spirometric values, or gas transfer and benefit from supplemental oxygen. No statistical correlation was found between resting $\mathrm{PaO}_{2}$ and benefit from oxygen. Almost all patients achieving an increase in exercise tolerance of greater than $50 \%$, however, were hypoxaemic at rest or showed appreciable desaturation during exercise. In patients with chronic obstructive airways disease the benefit was related to desaturation during the endurance but not the six minute walk.

The selection of patients likely to benefit from supplemental oxygen is difficult. We would recommend that patients should have a $50 \%$ greater exercise tolerance during either an endurance or a six minute walk than during an unburdened walk to be considered for portable supplemental oxygen. This study confirms that those patients with arterial hypoxaemia or appreciable arterial desaturation on exercise are the most likely to benefit. Only two patients achieved a useful improvement in endurance distance with oxygen in the absence of arterial hypoxaemia and without arterial desaturation during exercise. We suggest that exercise testing is undertaken only when one of these conditions is present.

We observed, like others, ${ }^{3}$ that many patients without arterial hypoxaemia or appreciable desaturation experienced a significant reduction in respiratory distress with supplemental oxygen during or on completion of exercise. The physiological mechanism for this benefit cannot readily be explained. The relief of exercise related dyspnoea in relation to the patient's quality of life may require further assessment.

Both the six minute walk and the endurance test gave highly repeatable results with standardised encouragement once the effect of learning was complete. Performance in the six minute walk was slightly more repeatable. In contrast, the learning effect of the endurance test was only $3.6 \%$, compared with $17 \%$ for the six minute walk. A single practice walk was sufficient for the endurance walk whereas two were necessary for a six minute walk. Oxygen increased performance in the endurance test because patients walked for longer rather than at greater speed. This is consistent with previous reports that oxygen increases the endurance of submaximal exercise but not the maximal work load. ${ }^{1}$ Instructions for the endurance walk are simple and the test is easily and quickly performed. Endurance testing may be more practical for the routine assessment of the benefit of oxygen therapy than the six minute walk.

Liquid oxygen is expensive because of the delivery charges and is not available on prescription. The portable pack is filled from a home reservoir that provides a 10-14 day supply, depending on use and the rate of evaporation. Breath activated systems have been developed and may provide an extended supply. Liquid oxygen systems are regarded as necessary for mobility in the United States, ${ }^{18}$ but patients' attitudes are probably different in the United States and in Britain. A pilot study by Wedzicha and colleagues showed that patients increased their activity and their use of oxygen when provided with a liquid rather than a gaseous supply. ${ }^{21}$ Greater acceptability to patients probably also explains the increased mobility and overall use of oxygen associated with transtracheal delivery, which avoids uncomfortable (and unsightly) oxygen masks or nasal prongs. ${ }^{17}$ Further trials of the acceptability of different systems are required in Britain.

We wish to express our thanks to Air Products plc for the provision of liquid oxygen and Omnicare Ltd for the Care Ease system. Miss $\mathbf{S}$ Chinn is funded by the Department of Health Miss G O'Connell performed the lung function tests and assisted with the exercise testing.

1 Bradley BL, Garner AE, Billiu D, Mestas JM, Forman J Oxygen-assisted exercise in chronic obstructive lun disease. Am Rev Respir Dis 1978;118:239-43.

2 Stein DA, Bradley BL, Miller WC. Mechanisms of oxygen effects on exercise in patients with chronic obstructive pulmonary disease. Chest 1982;81:6-10.

3 Woodcock AA, Gross ER, Geddes DM. Oxygen relieve breathlessness in "pink puffers." Lancet 1981;i:907-9.

4 Cotes JE, Gilson JC. Effect of oxygen on exercise ability in chronic respiratory insufficiency. Lancet 1956;ii:872-6.

5 Bye PTP, Anderson SD, Woolcock AJ, et al. Bicycle endurance performance of patients with interstitial lung disease breathing air and oxygen. Am Rev Respir Dis 1982 126:1005-12

6 Davidson AC, Leach R, George RJD, Geddes DM Supplemental oxygen and exercise ability in chronic obstructive airways disease. Thorax 1989;43:965-71.

7 Leggett RJE, Flenley DC. Portable oxygen and exercise tolerance in patients with chronic hypoxic cor pulmonale. BMJ 1977;ii:84-6.

8 McGavin CR, Gupta SP, McHardy GJR. Twelve-minute walking test for assessing disability in chronic bronchitis. BMJ 1976; ;:822-3.

9 Butland RJA, Pang J, Gross ER, Woodcock A, Geddes DM Two-, six-, and 12-minute walking tests in respiratory disease. $B M J 1982 ; 284: 1607-8$.

10 Guyatt GH, Pugsley SO, Sullivan MJ, Thompson PJ, Berman LB, Jones NL, et al. Effect of encouragement on walking test performance. Thorax 1984;39:818-22.

11 Cockcroft A, Beaumont A, Adams L, Guz A. Arterial oxygen desaturation during treadmill and bicycle exercise in patients with chronic obstructive airways disease. Clin Sci 1985;68:327-32.

12 Chinn S. Statistics in respiratory medicine. 3-Scale, parametric methods, and transformations. Thorax 1991; 46:536-9.

13 Chinn S. Statistics in respiratory medicine. 2-Repeatability and method comparison. Thorax 1991;46:454-6.

14 Medical Research Council Working Party. Long term 
domiciliary oxygen therapy in chronic hypoxic cor pulmonale complicating chronic bronchitis and emphysema. Lancet $1981 ; \mathrm{i}: 681-5$.

15 Stark RD, Finnegan P, Bishop JM. Long term domiciliary oxygen therapy in chronic bronchitis with pulmonary hypertension. $B M J$ 1973;iii:467-70.

16 Department of Health and Social Security. National Health Service England and Wales: amendments to drug tariff. London: DHSS, 1985. (DTA/IZ.)

17 Bloom BS, Daniel JM, Wiseman M, Knorr RS, Cebul R, Kissick WL. Transtracheal oxygen delivery and patients with chronic obstructive pulmonary disease. Respir Med 1989;83:281-8.
18 Conference report: Further recommendations for prescribing and supplying long term oxygen therapy. Am Rev Respir Dis 1988;138:745-7.

19 Lane R, Cockcroft A, Adams L, Guz A. Arterial oxygen saturation and breathlessness in patients with chronic obstructive airways disease. Clin Sci 1987;72:693-8.

20 Swinburn CR, Wakefield JM, Jones PW. Relationship between ventilation and breathlessness during exercise in chronic obstructive airways disease is not altered by prevention of hypoxaemia. Clin Sci 1984;67:515-9.

21 Lock SH, Blower G, Prynne M, Wedzicha JA. Comparison of liquid and gaseous oxygen for domiciliary portable use. Thorax 1992;47:98-100.

\section{The early days of lobectomy for bronchiectasis}

Lobectomy became a feasible procedure in the late 1920 s. At that time the technique consisted in freeing the lobe towards the hilum in the plane of the fissure, applying a snare as near the hilum as possible, tightening it to occlude the vessels and bronchus, lopping off the lobe, and sewing up the stump with multiple sutures before removing the snare. Formal dissection and ligature of vessels and closure of bronchial stump did not become standard practice until well into the 1930 s. The snare technique was often complicated by infection of pleura, and empyema was an almost expected postoperative incident; patients might be in hospital for six or eight weeks after operation. Nevertheless, it was strongly advocated for patients with bronchiectasis limited to one lobe. Bronchiectasis of this sort was then not infrequent; so when I was asked to present a demonstration of bronchiectatic lobes removed at the Brompton Hospital for the meeting of the Association of Physicians in London in $1935 \mathrm{I}$ was able to assemble 100 specimens.

Looking back on this experience, I wonder how far the frequency of these operations was determined by a feeling that if a new and exciting procedure can be done it ought to be done. Certainly there was no possibility at that time of the sort of randomised trial that would be required to find out how much good they did; and it remains difficult to devise acceptable trials of any sort of surgical procedure, or of any procedure that is thought to be helpful to selected patients. I formed the strong opinion that commonsense assessment of whether the patient's symptoms could be related to suppurative changes in the part of the lung it was proposed to remove was the best criterion for recommending surgery. If the expectoration of purulent sputum or haemoptysis as the leading symptom, without generalised wheeze or other indication of changes in undilated bronchi in the rest of the lung, relief of symptoms could be expected; but in the presence of such generalised changes results were likely to be disappointing. The temptation to hope that removal of a bronchiectatic lobe in a wheezy, "catarrhal" child would help was hard for some people to resist. I remember one such child in whom, in 1939 , I resisted this temptation. In 1946, after I returned from war service, she turned up at my clinic minus a lobe but with the same symptoms with which she had presented six years earlier. Someone else had succumbed to the temptation to remove the lobe containing the dilated bronchi. The operation had, of course, been performed by the more refined dissection technique; but the postoperative course had been complicated, leading to bronchiectasis in a previously unaffected part of the lung - and she was still wheezy.

GUY SCADDING 